Universal Decimal Classification (UDC) number 614.71: 711.5

\title{
METHODICAL APPROACHES TO INCREASING THE ACCURACY OF EXPOSURE ASSESSMENT BASED ON THE CONJUGATION OF SIMULATION AND MONITORING DATA ON AMBIENT AIR QUALITY
}

\author{
I.V. May, S.V. Kleyn, V.M. Chigvintsev, S.Yu. Balashov \\ FBSI «Federal Scientific Center for Medical and Preventive Health Risk Management Technologies», Russian \\ Federation, Perm, 82 Monastyrskaya St., 614045
}

\begin{abstract}
To achieve a correct assessment of population inhalation exposure, the method of conjugation of the results of pollutant instrumental measurements and calculation of dispersion of pollutants from emissions from stationary and mobile sources, was proposed and tested. The method is based on determination of the conformity coefficients between the calculated concentrations and the monitoring data for pollutant measurements at specific points (for example, at monitoring site points) and on solving of a problem of approximation of spatial data using the obtained coefficients. This is performed by solution of linear algebraic equation system for the points inside the triangles, formed in a given area according to the Delaunay triangulation.

Testing and verification of the method as exemplified by a large industrial centre, indicates a 1.5-4-fold increase in the accuracy of ground-level concentration prediction in comparison with the accuracy achieved using the method of approximation of the monitoring site data using inverse distances or calculations of dispersion. The method provides more correct territorial zoning and determination of a population size under conditions of short and/or long-term (chronic) exposure.
\end{abstract}

Key words: ambient air, exposure assessment, dispersion calculation, instrumental measurements, predictive accuracy.

High quality exposure assessment is an integral part of the correct health risk assessment and, consequently, of the reliability and accuracy of the entire system of the decision-making based on its results. Several national and international studies focused on the analysis of health risk under conditions of exposure to air pollutants, were carried out using calculations of dispersion of emissions from individual stationary sources and vehicles, or their combination [2, 8]. Calculated estimate of dissemination of emission components has several benefits: it allows generation of a full dimensional model of the area pollution, makes it possible to determine the concentration at any point within the study area, to assess the change in concentrations depending on the defined meteorological conditions, operation regimens of stationary sources and/or traffic concentration.

Analysis of pollution maps with the account of the location of residential construction

(C) May I.V., Kleyn S.V., Chigvintsev V.M., Balashov S.Yu., 2013

Mai Irina Vladislavovna (Perm, Russia) - DSc, Professor, Deputy Director for Science (e-mail: may@fcrisk.ru; tel.: 8 (342) 237-25-47).

Kleyn Svetlana Vladislavovna - PhD, Head of the Department of Sanitary and Hygienic Analysis and Monitoring Systemic Methods (e-mail: kleyn@fcrisk.ru; tel.: 8 (342) 237-18-04).

Chigvintsev Vladimir Mikhaylovich - fellow research of Situation Modeling and Expert and Analytical Management Techniques Laboratory (e-mail: cvm@fcrisk.ru; tel.: 8 (342) 237-18-04).

Balashov Stanislav Yurjevich - Head of the Sanitary and Hygienic Analysis and Expert Examinations Laboratory (e-mail: stas@fcrisk.ru; tel.: 8 (342) 237-18-04). 
allows assessment of the exposure distribution in terms of population size, and isolation of the contingents which have the highest exposure. Essential is also the possibility to determine a particular source of air pollution and, ultimately, of the health risk. The disadvantage of the calculation method is the dependence of the trueness of the concentration values of pollutants present in the atmosphere on reliability of the input parameters, quality of the selected mathematical model and adequacy of the information needed for implementation of this model $[8]$.

To avoid inaccuracies of calculation methods, some scientists apply direct instrumental studies, which provide more accurate assessment of quality of the environment $[1,7,14]$. Often such methods of exposure analysis are given preference over the results of calculations. However, it should be noted that the direct measurement of the environmental quality always characterizes the state of the environment at the current moment or during a period of time at a particular point of the area. The level of reliability of the field studies in terms of the assessment of spatial differences of points on the area, is not high enough and highly dependent on the number of monitoring sites, located in this area. For the areas of large industrial centres, a significant number of monitoring sites is required to generate a quite correct spatial pollution map of the city $[8,10]$. Thus, the problem of inter- and extrapolation of the data obtained from monitoring sites to adjacent and remote areas remains acute. The literature describes methods for data interpolation (inverse distance method, kriging, Shepard's Method, triangulation with linear interpolation, etc.) $[3,12,13]$. The methodology of calculation of a pollution level according to the data of fixed monitoring sites of the Federal Service of Russia on Hydrometeorology and Monitoring of the Environment is based on the inverse distance method, which is currently used most widely for interpretation of the data on ambient air quality, including calculation of the background pollutant concentrations [10]. However, all the above methods are focused on transformation of only instrumental measurements or only calculations.

In this context, the task of developing a method combining the positive aspects of simulation and instrumental measurements for adequate assessment of ambient air quality over a large area, where a large population is exposed to emissions from stationary and mobile sources of pollution, seems relevant and promising.

Study goal - development and testing of methodological approaches for quality improvement of the assessment of a large-city population inhalation exposure based on conjugation of calculation and field data on the ambient air quality.

Materials and methods. Perm was chosen as an object of investigation. This city is a regional centre, characterized by continuously elevated levels of atmospheric pollution. 
Calculations of the dispersion of pollutants was performed using standardized programs for calculations of atmospheric pollution, "Ecologist-City" and "Ecologist-mean values" that implement a mathematical OND-86 calculator and amendments to this document [5, 6]. A database including information about 11,200 stationary sources of industrial enterprise emissions and organizations of the city was used. The data were obtained from the inventory records of economic entities (based on actual projects on maximum permissible emission levels or sanitary protection zones of enterprises). All sources were referenced to the city vector map in the local coordinate system and characterized by geometric and aerodynamic parameters and the data on the mass of each pollutant emission (gram/second, tonne/year), sufficient to perform the calculations of dispersion according to the OND-86 method, standardized for the Russian Federation ${ }^{1}$.

Calculations of dispersion of hazardous substances were performed for several points of the stationary monitoring sites in the area of the city and for 176,000 of regular grid points (design rectangle $50500 \times 34800 \mathrm{~m}$ ) under different weather conditions and averaging periods.

At the same time, using "Magistral" software complex, calculations of emissions $(\mathrm{g} / \mathrm{sec}$, tonne/year) were performed for 1329 sites of street and road network of the city, taking into account the intensity and structure of traffic flows (the sites analysed accounted for $85 \%$ of the total length of the street and road network of the city), taking into account the hourly dynamics of the variability of the indicated flow parameters.

The data on single, average daily and average annual concentrations of 40 chemical pollutants measured at 7 observation sites of the Federal Service of Russia on Hydrometeorology and Monitoring of the Environment, were provided by the Perm Centre for Hydrometeorology and Environmental monitoring. The information on concentrations was accompanied by the information on meteorological parameters under which all measurements were performed.

All studies were carried out using standardized methods and verified measurement tools.

To verify the method at 14 points located in the area of the city, which were not included in the calculations, the Federal State-Funded Healthcare Institution „Centre for hygiene and epidemiology in Perm Krai“ and the laboratory-research centre of the Federal Budget Scientific Institution "Federal Scientific Center for Medical and Preventive Health Risk Management Technologies" carried out additional instrumental measurements. The location of the monitoring

\footnotetext{
${ }^{1}$ Technical document reflecting the comparison of the model used in the Russian Federation with the American Gaussian model for calculation of atmospheric pollution, which suggests that the results of air pollution calculations performed according to each of the compared methods, are similar [14].
} 
sites and the points for instrumental measurements are shown on Figure 1. The measurement results were shown as formalized tables or research protocols.

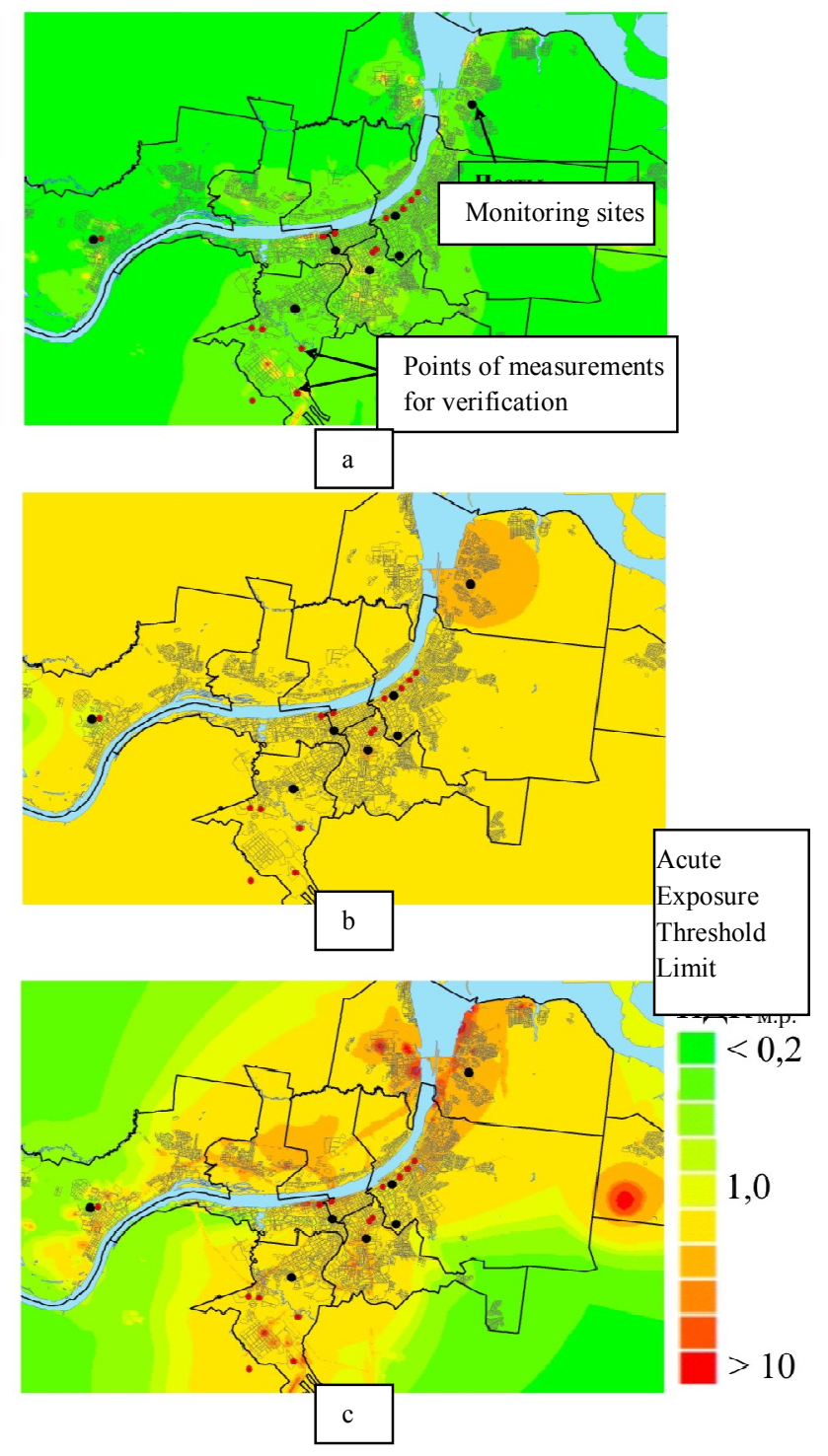

Figure 1. Spatial distribution of ambient air pollution by nitrogen dioxide in Perm (summer 2012, calm, temperature $\left.25-26^{\circ} \mathrm{C}\right)$ : according to the data on the dispersion calculations $(a)$, with the account of approximation of the data from the monitoring sites using the inverse distance method $(b)$, with the account of the data approximation using the proposed method $(c)$

All sampling points were plotted on the area map and had a grid lock in the coordinate system of the city. For a comparative assessment of the proposed approaches, the spatial analysis was performed using the inverse distance method, offered in the Guidance RD 52.04.186-89 [10].

This method is based on determination of the "centre of gravity" of the monitoring site net - a point, coordinates of which are the arithmetic mean of the corresponding coordinates 
Scientific and methodical approaches to risk analysis

of monitoring sites, and on interpolation of the data within a circle with a radius of $1.1 \mathrm{R}$, where $\mathrm{R}$ is a distance between the "centre of gravity" and the outermost monitoring site, according to the formula

$$
C_{x, y}=\frac{\sum C_{k} / r_{k}}{\sum 1 / r_{k}},
$$

where $C_{k}$ are the determined concentrations at the $k$-th monitoring site and in the selected point (for the corresponding gradation of wind speed and direction); $r k$ is a distance from the selected point $(x, y)$ to the $k$-th monitoring site.

Extrapolation outside the circle is carried out by the formula

$$
C_{x, y}=\frac{\sum C_{k} / r_{k}}{\sum 1 / r_{k}^{0}}+c\left(1-1,1 \frac{R}{r^{0}}\right),
$$

where $r_{k}{ }^{0}$ is a distance from the $k$-th monitoring site to the point of intersection of the circle and the line connecting the selected point with the centre of gravity; $r^{0}$ is a distance from the selected point to the centre of gravity, and $c$ is an "out-of-city" background [8].

The results of the data processing were displayed using a geographic information system ArcCGIS 9.3, using a vector map of the area. To assess the exposure, isolines of pollution levels were crossed with thematic layers that characterize the locations of children's educational institutions, residential areas, recreational areas, etc.

Results and discussion. A method for estimating of a population exposure based on the conjugation of the calculated and instrumental data on air quality is based [4], which is implemented through the following sequential steps:

- Formation of an updated maximally complete electronic database of stationary and mobile sources of air pollution in the studied area;

- Dispersion calculations on a regular grid with as frequent as possible step along the rectangle which covers the entire studied area;

- Calculation of ground-level concentrations at each point, where the instrumental measurements were performed. For the annual data approximation, as such points the locations of the fixed sites of the Federal Service of Russia on Hydrometeorology and Monitoring of the Environment were considered, for approximation of the data of single pollution levels all locations of instrumental measurements were considered, including those performed during fixed-route, mobile or other studies;

- Calculation of correspondence coefficients in the points of instrumental measurements for the purpose of conjugation of the calculated concentrations of pollutants and the 
monitoring data in accordance with the formula

$$
K_{i}=\frac{C_{i}^{p}}{C_{i}^{y}},
$$

where $i$ is the point (monitoring site) number;

$C_{i}^{r}$ are calculated concentrations of the pollutant at the $i$-th monitoring site;

$C_{i}^{p}$ are real concentrations of the pollutant at the $i$-th monitoring site.

Comparison of the calculated concentrations of pollutants and the monitoring data when conjugating single concentrations are performed only for uniform meteorological conditions;

- connection of the monitoring site points using Delaunay triangulation with noncrossing line segments, such that a new segment could not be added without crossing with existing one [2];

- determination of belonging of each point located inside the polygon formed by the outer points of instrumental measurements, to one of the formed triangles, with the following conditions: the segments connect the point with the corners of each triangle; if the area of the original triangle is equal to the sum of the areas of the three triangles formed $S=S_{1}+S_{2}+S_{3}$, it is considered that the point does belong to the triangle; and if $S<S_{1}+S_{2}+S$ - the point does not belong to this triangle;

- calculation of the conformity coefficient for all points inside a polygon. It was considered that the distribution of the conformity coefficient inside the polygon formed by the points of monitoring sites, represents a continuous linear function of two variables, which can be written as follows:

$$
K(x, y)=a_{0}+a_{1} x+a_{2} y,
$$

where $a_{0}, a_{1}, a_{2}$ are arbitrary constant coefficients.

Conformity coefficients at the sites forming a triangle were referred to as $k_{1}, k_{2}, k_{3}$; the solution of the system of three linear algebraic equations in $a_{0}, a_{1}$, and $a_{2}$ unknown coefficients

$$
k_{i} \equiv K\left(x_{i}, y_{i}\right)=a_{0}+a_{1} x_{i}+a_{2} y_{i}, i=1,3 .
$$

The solution of the system (5) provided an unambiguous expression of the function (4) through its nodal values and coefficients at all points lying inside the polygon formed by the points of instrumental measurement sites;

- extrapolation of the conformity coefficient values for the points lying outside the polygon formed. Coefficient values for these points were taken as equal to the coefficients at the nearest point lying on the boundary of the polygon formed by the points of instrumental measurements. Approximated values of the conformity coefficient were obtained in all grid 
points;

- calculation of pollutant concentrations for each of the target points of the studied area, according to the formula (4):

$$
C^{r}(x, y)=K(x, y) \cdot C^{p}(x, y)
$$

where $C^{r}$ are approximated pollutant concentrations at the target point $(x, y) ; K$ is a conformity coefficient at the target point (x, y); $C^{p}$ are total calculated pollutant concentrations (emissions from stationary sources and vehicles) at the target point $(x, y)$.

The results obtained included the values of ground-level concentrations of pollutants, including the values at the points of the regular grid covering systemically the whole investigated area, where inter- and extrapolation of stationary monitoring sites were adjusted with the account of the distribution of pollutants from real sources of the ambient air pollution, such as industrial plants, highways, etc. At the points of instrumental measurements (monitoring sites) the concentration always represented the true measured value (for given meteorological conditions), and the change in the content of pollutants across the area was accounted for through the simulation results.

Implementation of a number of calculations for the system of points covering the entire city area, and directed field studies provide data for comparative analysis of simulation results and instrumental measurements.

The following table provides as an example statistical parameters of comparison of the predicted concentrations of nitrogen dioxide with the measured ones at 14 locations. For verification of the method, adverse weather conditions were selected as those which allow the best elimination of uncertainties associated with unstable wind speed and direction.

The data obtained suggested that dispersion calculations provided systematically underestimated results. For none of the points the actual concentrations were obtained at the level equal to or below the values calculated on the basis of a consolidated database on the sources. Absolute error for predicted levels ranged in the context of the particular study from 0.11 to $1.5 \times$ Acute Exposure Threshold Limit, which in general does not allow using these results for reliable assessments of health risks.

Mean absolute errors of the inverse distance method, when only data of stationary sites are used, and of the method of conjugation of field and calculated data, were lower and their absolute values were, respectively, 0.465 and $0.255 \times$ Acute Exposure Threshold Limit with error ranges from -0.680 to 1.0 and from $-0,240$ to 0,410 , respectively. In this case the standard 
deviation, which characterizes a variational series scattering, was almost twice lower when using the developed method.

\section{Prediction errors for ground-level concentrations of nitrogen dioxide in ambient air of Perm (calm, wind speed of $0-0.5 \mathrm{~m} / \mathrm{s}$, air temperature $25-26^{\circ} \mathrm{C}$ )}

\begin{tabular}{|c|c|c|c|c|c|c|}
\hline \multirow{2}{*}{$\begin{array}{c}\text { Point } \\
\text { number }\end{array}$} & \multicolumn{2}{|c|}{$\begin{array}{c}\text { Point } \\
\text { coordinates }\end{array}$} & $\begin{array}{c}\text { Measured } \\
\text { value, Portion } \\
\text { of acute } \\
\text { exposure } \\
\text { threshold } \\
\text { limit }\end{array}$ & $\begin{array}{c}\text { Calculation } \\
\text { method }\end{array}$ & $\begin{array}{c}\text { Approximation } \\
\text { of the monitoring site } \\
\text { data using inverse } \\
\text { distance method }\end{array}$ & $\begin{array}{c}\text { Approximation } \\
\text { Using conjugation of } \\
\text { calculated and field data }\end{array}$ \\
\hline 1 & 2572 & 888 & 1,1000 & 0,6629 & $-0,175$ & 0,160 \\
\hline 2 & 3854 & 1641 & 1,3200 & 1,1085 & 0,511 & 0,418 \\
\hline 3 & 4395 & 2285 & 2,4000 & 1,1200 & 1,003 & $-0,242$ \\
\hline 4 & 4884 & 2883 & 1,9200 & 1,0300 & 0,520 & 0,200 \\
\hline 5 & -1086 & -305 & 2,1500 & 0,8800 & 0,510 & 0,290 \\
\hline 6 & -1926 & -547 & 2,1440 & 1,5559 & 0,282 & $-0,225$ \\
\hline 7 & 1671 & -1835 & 0,9500 & 1,1928 & 0,710 & 0,360 \\
\hline 8 & 1915 & -1529 & 1,4500 & 0,7800 & $-0,240$ & 0,400 \\
\hline 9 & -3475 & -9303 & 1,2700 & 0,9868 & $-0,429$ & $-0,180$ \\
\hline 10 & -7050 & -7700 & 1,4200 & 1,3041 & $-0,054$ & $-0,192$ \\
\hline 11 & -6275 & -7825 & 1,9100 & 1,4654 & $-0,680$ & 0,150 \\
\hline 12 & -7007 & - & 1,3500 & 1,0912 & 0,450 & 0,294 \\
\hline 13 & -3779 & - & 2,1500 & 1,3200 & $-0,590$ & $-0,240$ \\
\hline 14 & -11580 & 2690 & 1,1000 & 0,1100 & $-0,365$ & 0,255 \\
\hline \multicolumn{3}{|c|}{ Mean absolute error $(|\Delta|)$} & 1,043 & 0,465 & 0,2681 \\
\hline \multicolumn{3}{|c|}{ Standard deviation $(\sigma)$} & 1,101 & 0,521 & \\
\hline
\end{tabular}

No relationships between the deviation of the calculated data from the measured values for the results obtained using different methods have been found.

Similar results were also obtained by comparing the predicted and measured data on sulfur dioxide, benzene and phenol. In general, the results of calculations indicated that the proposed methodological approaches can improve the accuracy of assessment of pollutants in the ambient air.

Since the exposure is a measure of contact of a hazardous factor with a human, the spatial analysis of air quality in the city and the assessment of the exposed population seemed very important from the standpoint of the proposed method.

It was found that conjugation of calculated and field data significantly altered the idea of the spatial pollution distribution in the city area (see Figure 1).

So, it was found that during adverse weather conditions the zone of ambient air pollution with nitrogen dioxide covers much greater area than the area predicted by simulation. Accordingly, the part of the population which is under exposure higher that $1 \times$ Acute Exposure 
Threshold Limit, may consist of more than 800 thousand people (with the total amount of about 12 thousand according to calculations). Pollution pattern was significantly more detailed when approximated data were compared with the results obtained using the inverse distance methods, according to which almost all the city area was characterized by a uniform pollution level of 2-4 $\times$ Acute Exposure Threshold Limit.

Similar results were obtained with the spatial analysis for other pollutants, such as nitrogen oxide, carbon monoxide, ammonia, hydrogen chloride, phenol. A significant result of application of the developed approaches was the updating of spatial characteristics of the average annual ambient air pollution of the area and isolation of the zones with such level of exposure which suggested an unacceptable risk to public health (Figure 2).

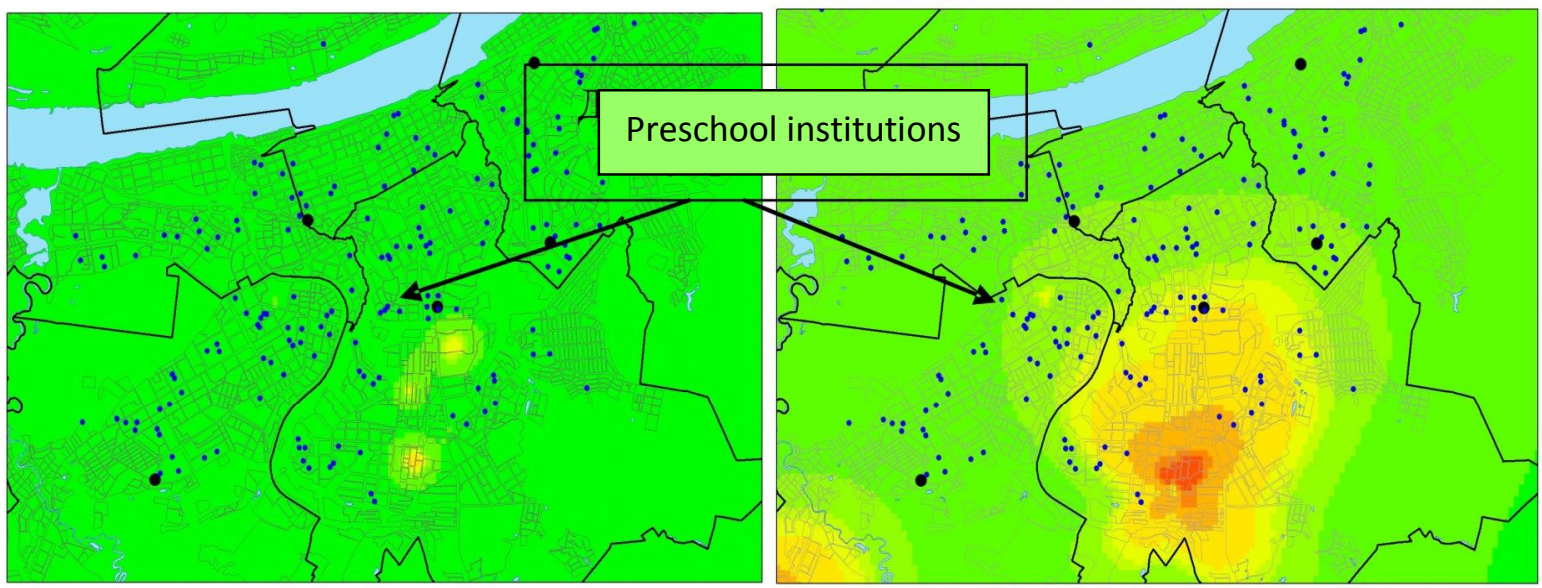

$a$

6

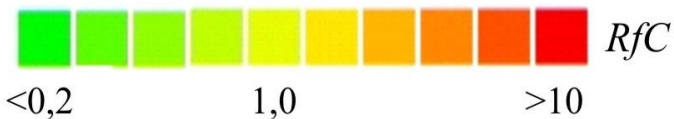

Figure 2. Zoning of the city area according to the level of the average phenol concentration in the ambient air and location of preschool institutions in the areas of varying exposure according to calculations of dispersion

(a), taking into account the data approximation performed by the proposed method (b)

Thus, it was determined that more than 20 preschool institutions and a significant part of the housing of one of the city districts are located in the zone influenced by the sources of phenol emission, under conditions of the average ground-level concentration at the level above referent values for chronic exposure $\left(0.06 \mathrm{mg} / \mathrm{m}^{3}\right)$.

According to the results of conjugation analysis, several areas were isolated with the average levels of pollution of atmospheric air with benzene above reference concentrations $\left(0.03 \mathrm{mg} / \mathrm{m}^{3}\right)$. The population exposed to this level of pollution is over 80 thousand people. The zones exposed to the levels above reference chronic exposure levels for some heavy metals, fluoride, and hydrogen sulfide were identified and described. Such zones had different 
populations (from 2.0 to 140 thousand people) and different levels of exposure. However, all these areas and characterization of the resident population require in-depth studies on hygiene, including the assessment of health risks and development of programs of prevention and rehabilitation measures.

During testing of methodological approaches it was determined that conjugation of calculated and field data on such pollutants as formaldehyde, hydrogen chloride, and various kinds of dusts for the studied area is not feasible due to extremely significant exceeding of values of the actually measured concentrations above the calculated ones (conformity coefficients at the monitoring site points reached 200 or more, with the optimum of 1.0). This was suggestive of either poor quality of the data on emission sources, or the need to account for the processes such as pollutant transformation.

In general, the proposed methodological approaches, based on conjugation of calculated data and the results of instrumental measurements on the ambient air quality, provide increased accuracy of assessments of the content of hazardous pollutants in ambient air, improve the reliability of the spatial analysis with allocation of the zones of potential unacceptable health risk and determination of population size living under exposure to hazardous factors.

\section{References}

1. Berezhnaja E.V. Ocenka riska dlja zdorov'ja naselenija g.Voronezha pri vozdejstvii himicheskih veshhestv, zagrjaznjajushhih atmosfernyj vozduh [Human health risk assessment of exposure to chemical substances polluting ambient air in the city of Voronezh]. Modelirovanie, optimizacija i informacionnye tehnologii, 2013, no. 1, pp. 1-6.

2. Bobkova T.E. Znachenie funkcional'nogo zonirovanija goroda [The meaning of urban functional zoning]. Zdorov'e naselenija i sreda obitanija, 2009, no. 6, pp. 11-14.

3. Djevis DZh. S. Statisticheskij analiz dannyh v geologii [Statistical data analysis in geology]. Moscow: Nedra, 1990. Vol. 1-2.

4. Monitoring kachestva atmosfernogo vozduha dlja ocenki vozdejstvija na zdorov'e cheloveka [Ambient air quality monitoring for health impact assessment]. Regional'nye publikacii WHO, Evropejskaja serija, Praga: WHO, 1997, no. 85. 288 p.

5. Mishina A.L. ispol'zovanie metodologii ocenki riska dlja upravlenija kachestvom atmosfernogo vozduha [Using the risk assessment methodology for ambient air quality management]. Zdorov'e naselenija i sreda obitanija, 2009, no. 6, pp. 26-29.

6. Rukovodstvo po kontrolju zagrjaznenija atmosfery. RD 52.04.186-89 [Guidelines on air pollution monitoring. RD 52.04.186-89]. Moscow, 1991. $641 \mathrm{p}$.

7. Gasilin V.V., Bocharov E.P., Vahitov K.H., Popov G.O., Ajzatullin A.A. Sanitarnogigienicheskaja ocenka atmosfernogo vozduha i ocenka kancerogennogo riska dlja zdorov'ja naselenija $\mathrm{v}$ krupnom promyshlennom gorode [Environmental health assessment of ambient air and carcinogenic risk assessment in a large industrial city]. Zdorov'e naselenija $i$ sreda obitanija, 2013, no. 4 (241), pp. 42-44.

8. Skvorcov A.V. Trianguljacija Delone i ee primenenie [Delaunay triangulation and its application]. Tomsk: Izd-vo Tomskogo un-ta, 2002. 128 p.

9. Centr Prostranstvennyh Issledovanij. Geostatisticheskij analiz [Centre for Spatial 
Research. Geostatistical analysis], available at: http://www.geointellect.spb.ru/?id=157.

10. Shajgardanova Ch.H., Hamitova R.Ja. Ocenka riska, obuslovlennogo zagrjazneniem atmosfernogo voduza, dlja zdorov'ja detej doshkol'nogo vozrasta g.Nizhnekamska [The assessment of a risk related to ambient air pollution in pre-school children in the city of Nizhnekamsk]. Prakticheskaja medicina, 2008, no. 30, pp. 115-116.

11. Shitikov V.K., Rozenberg G.S., Kostin N.V.. Metody sinteticheskogo kartografirovanija territorii (na primere jekologo-informacionnoj sistemy "VOLGABAS") [Methods for synthetic mapping of an area (a VOLGABAS environmental information system case study)]. Kolichestvennye metody jekologii i gidrobiologii (Sbornik nauchnyh trudov, posvjashhennyj pamjati A.I. Bakanova). Ed. chl.-korr. RAN G.S. Rozenberg. Tol'jatti: SamNC RAN, 2005, pp. 167-227.

12. Fushimi A., Kawashima H., Kajihara H. Source apportionment based on an atmospheric dispertion model and multiple linear regression analysis. Atmospheric Environment, 2005, vol. 39, no. 7, pp. 1323-1334.

13. Kwak B.K., Kim J.H., Yi J., Park H.-S., Kim N.G., Choi K. A GIS-based national Emission inventory of major VOCS and risk assessment. Part II - Quantitative verification and risk assessment using an air dispersion model. Korean Journal of Chemical Engineering, 2010, vol. 27 , no. 1, pp. 121-128.

14. Hanna, S.R., Review of Atmospheric Diffusion Models for Regulatory Applications. World Meteorological Organization Technical Note No. 177, Geneva, Switzerland: WMO, 1982, no. $581.42 \mathrm{p}$. 